\title{
In silico modelling and characterization of eight blast resistance proteins in resistant and susceptible rice cultivars
}

\author{
R. Chandrakanth", L. Sunil ${ }^{2}$, L. Sadashivaiah ${ }^{1}$ and N. S. Devaki ${ }^{1 *}$
}

\begin{abstract}
Background: Nucleotide-binding site-leucine-rich repeat (NBS-LRR) resistance genes are the largest class of plant resistance genes which play an important role in the plant defense response. These genes are better conserved than others and function as a recognition-based immune system in plants through their encoded proteins.

Results: Here, we report the effect of Magnaporthe oryzae, the rice blast pathogen inoculation in resistant BR2655 and susceptible HR12 rice cultivars. Transcriptomic profiling was carried out to analyze differential gene expression in these two cultivars. A total of eight NBS-LRR uncharacterized resistance proteins (RP1, RP2, RP3, RP4, RP5, RP6, RP7, and RP8) were selected in these two cultivars for in silico modeling. Modeller 9.22 and SWISS-MODEL servers were used for the homology modeling of eight RPs. ProFunc server was utilized for the prediction of secondary structure and function. The CDvist Web server and Interpro scan server detected the motif and domains in eight RPs. Ramachandran plot of eight RPs confirmed that the modeled structures occupied favorable positions.

Conclusions: From the present study, computational analysis of these eight RPs may afford insights into their role, function, and valuable resource for studying the intricate details of the plant defense mechanism. Furthermore, the identification of resistance proteins is useful for the development of molecular markers linked to resistance genes.
\end{abstract}

Keywords: In silico analysis, Rice blast, NBS-LRR, Resistance proteins, Homology modeling

\section{Background}

Rice is the most important food crop in the world and a primary source of food for more than half of the world's population. The causal agent, Magnaporthe oryzae B.C. Couch, has been used for several decades as a model organism for understanding the mechanism underlying the host and fungal pathogen interaction [1]. The most important group of genes that have been used by breeders for disease control is the plant resistance $(\mathrm{R})$ genes. Hence, building up a host resistance gene repertoire is of prime concern [2]. Resistance genes (R) are members of a very large multigene family, and these $R$

\footnotetext{
* Correspondence: devakineerkaje@gmail.com

Chandrakanth $R$ and Sunil $L$ contributed equally to this work

'Department of Molecular Biology, Yuvaraja's College, University of Mysore,

Mysuru, Karnataka 570005, India

Full list of author information is available at the end of the article
}

genes are distributed throughout the 12 rice chromosomes except for chromosome 3 [3]. The rice plants are protected against the pathogens, upon infection, by inducing defense mechanisms via the induction of hypersensitive response (HR), which occurs via gene-forgene recognition of a pathogen effector and a rice plantencoded resistance $(R)$ protein [4]. The majority of rice blast resistance genes encode proteins that have a putative central nucleotide-binding site (NBS) and carboxy-terminal leucine-rich repeats (LRR). These NBS-LRR proteins are divided into two major classes: the first class has an $\mathrm{N}$-terminal domain that shares homology with the mammalian Toll-interleukin-1-receptor (TIR) domain while the second class encodes an amino-terminal coiled-coil motif (CC-NBS-LRR) [5].

Rice blast resistance genes are usually constitutively expressed in plants [6]. Major blast $\mathrm{R}$ genes like $\mathrm{Pi}$-ta,
Springer Open (c) The Author(s). 2020 Open Access This article is licensed under a Creative Commons Attribution 4.0 International License, which permits use, sharing, adaptation, distribution and reproduction in any medium or format, as long as you give appropriate credit to the original author(s) and the source, provide a link to the Creative Commons licence, and indicate if changes were made. The images or other third party material in this article are included in the article's Creative Commons licence, unless indicated otherwise in a credit line to the material. If material is not included in the article's Creative Commons licence and your intended use is not permitted by statutory regulation or exceeds the permitted use, you will need to obtain permission directly from the copyright holder. To view a copy of this licence, visit http://creativecommons.org/licenses/by/4.0/. 
Pi-d3, Pi-b, Pi-k1, and RGA were cloned and studied. These blast $\mathrm{R}$ genes encode Nod-like receptor (NLR) family proteins that may directly or indirectly interact with fungal effectors to trigger immunity [7].

Reports on structural studies of proteins encoded by blast resistance genes are scanty. Pita and pi54 are the examples of the characterized proteins, and other than these, relatively little is known about the downstream interacting partners of plant NBS-LRR proteins $[5,8]$.

Crystal structures of mammalian NBS and LRR domains are taken as templates for homology-modeling approaches as complete structures are not available for plant NBS-LRR proteins [9]. NBS-LRR proteins are known to be involved in defense mechanisms in plants. However, other functions carried out by these proteins and their mechanism of action have not been elucidated well. There are many reported protein sequences with functions yet to be experimentally confirmed. These uncharacterized proteins offer a potential for finding numerous applications as biological markers. This can be achieved by using various computational approaches to predict the three-dimensional structure and function of target proteins. Homology modeling is the most accurate method for the structure prediction of uncharacterized protein [10].

In the present study, we modeled eight blast resistance proteins obtained by in silico approach, which are expressed during host-pathogen interaction, predicted their diverse structures, and identified the different domains and binding sites. Structural analysis of these resistance proteins is important for understanding the interaction between $A v r$ effector proteins and resistance proteins which are the hallmark of plant defense mechanism.

\section{Methods}

\section{Plant materials and inoculation}

The seeds of resistant BR2655 and susceptible HR12 rice cultivars are collected from Zonal Agricultural Research Station, V.C. Farm, Mandya. These seeds were surfaces sterilized and grown in a greenhouse in a culture chamber $\left(14 \mathrm{~h} \mathrm{light} / 10 \mathrm{~h}\right.$ dark at temperature $\left.28 \pm 1{ }^{\circ} \mathrm{C}\right)$ for 20 days. The rice seedlings were sprayed with conidia at an inoculum concentration of $1 \times 10^{5}$ cells per milliliter containing $0.1 \%$ Tween-20. Seedlings which were mock inoculated with $0.1 \%$ Tween-20 solution served as control. After inoculation, the leaves were collected separately at $24 \mathrm{~h}$ intervals and immediately frozen in liquid nitrogen, and then stored at $-80^{\circ} \mathrm{C}$.

\section{RNA isolation}

Total RNA from rice plant tissues was extracted using the RNeasy Plant Mini Kit (Qiagen, Germany). The quantity and quality of RNA samples were determined using Nanodrop 2000 (Thermo Fisher Scientific) and Agilent 2100 Bioanalyzer (Agilent Technologies). Libraries were prepared using NEBNext ${ }^{\circ}$ Ultra $^{\text {six }}$ RNA Library Prep Kit for Illumina according to the sample preparation guide. Paired-end sequencing was performed with the TruSeq SBS Kit (Illumina Inc., USA) on Illumina NextSeq 500 (Illumina., USA) (Supplementary Data 2). The sequencing reads were filtered using default parameters for removing the low quality and contaminated reads using readqc analysis. The HQ reads after quality filtering was used for downstream analysis.

\section{Reference-based assembly and differential gene expression}

The overall work carried out in this study is presented in the flow chart (Supplementary Figure 1). High-quality clean reads were mapped to the rice reference genome RGAP7 (http://rice.plantbiology.msu.edu/) using a reference assembly tool of CLC Genomics Workbench and mapping parameters are presented in (Supplementary Table 4).

The rice blast resistance genes expressed in BR2655 and HR12 (upregulated > 3) cultivars were selected based on the keywords "Resistance" and "LRR" (Supplementary Table $2 \& 3$ ). Eight genes were shortlisted for the structure determination of their encoded proteins (Supplementary Table 1). Out of these, two genes were chosen from BR2655 and HR12 exclusively. The remaining four genes were selected based on their presence in both the cultivars. The transcripts with $\log _{2}$ fold change $\geq 3$ (upregulated genes) and $\leq 3$ (downregulated genes) with $P$ value cutoff of $\leq 0.05$ were considered as differentially expressed transcripts at a significant level. Eight proteins expressed by these eight genes were considered for further structural characterization.

\section{Amino acid sequence retrieval and analysis}

Amino acid sequences of NBS-LRR of eight resistance proteins (RP1, RP2, RP3, RP4, RP5, RP6, RP7, and RP8) were retrieved from the Rice Genome Annotation Project. The amino acid sequences of eight resistance proteins were stored as FASTA format sequence and used for further analysis (Supplementary Data 1). The physical and chemical parameters were determined by using the ExPASy Prot Param. The similarity search was performed against the non-redundant database in protein data bank (PDB), and PDB structures were used to search similar structures to that of eight RP proteins using PSI-BLAST tool [11].

\section{Homology modeling}

SWISS-MODEL server (https://swissmodel.expasy.org) [12] and Modeller 9.22 (https://salilab.org/modeller/download installation.html) [13] programs were used to build and 
generate the three-dimensional structures of eight resistance proteins. The three-dimensional structures were visualized with the UCSF Chimera program [14].

\section{Conserved motif structures and phylogenetic analysis of RP proteins}

The amino acid sequences of eight resistance proteins were subjected to domain and motif search by using The CDvist Web server [15] and Interpro scan server [16]. The eight resistant protein sequences were aligned for Multiple Sequence Alignment (http://www.ebi.ac.uk/ Tools/msa/muscle/) to observe the homology sequence alignment among resistance proteins using ClustalW [17]. The phylogenetic analysis was performed to see the evolutionary relationship among reported resistance genes such as Pita, Pid3, Pik2, Pib, Pi54, Pik1, RGA4, and RGA5 and the eight resistance proteins (RP1 to RP8).

\section{Structure and function analysis of RP}

The secondary structures of eight resistance proteins were predicted by using the RaptorX (http://raptorx. uchicago.edu) prediction server [18] and ProFunc server [19] which use methods such as fold matching, residue conservation, surface cleft analysis, and functional 3D templates [19].

\section{Validation of RP proteins}

The quality of the predicted three-dimensional structure models of eight resistance proteins was analyzed through SAVeS Server (https://services.mbi.ucla.edu/ SAVES/) [20] and SuperPose (http://wishart.biology. ualberta.ca/SuperPose/) [21].

\section{Results}

\section{Differential gene expression analysis}

Experiments on disease screening revealed the different stages of resistance between BR2655 and HR12 rice cultivars. BR2655 and HR12 seedlings inoculated with M. oryzae (M036) conidial suspension, showed disease scoring 2 (resistant), and 8 (susceptible) respectively based on the IRRI SES scale.

We observed the difference in gene expression profiling in BR2655 and HR12 rice cultivars during infection by $M$. oryzae. In total, we obtained 75.8 and 69.7 million raw reads for BR2655 and HR12 rice cultivars, respectively (Supplementary Data 3 and Supplementary Figure 2). We identified 7577 and 4290 differentially expressed genes (DEG) in the resistant line (R) (BR2655) and susceptible line (S) (HR12), respectively. As per the "LRR" keyword search, 22 transcripts, which are upregulated in BR2655 cultivar were shortlisted and with the "Resistance" keyword search, 36 transcripts were enlisted. Correspondingly, the upregulated transcripts were shortlisted in HR 12 cultivar using the same keyword search, and there were 17 and 38 transcripts, respectively.

\section{Amino acid sequence retrieval and analysis}

The amino acid sequences of eight RPs were retrieved from the RGAP. The eight RPs were analyzed for amino acid composition by the ExPASy ProtParam tool (Table 1). Leucine was the most frequent amino acid present in the sequence in all eight RPs and the percentage of leucine residues ranged from 11.4 to $15.0 \%$. RP5 was found to have the least percentage of leucine content, i.e., $11.5 \%$, and RP2 showed the highest percentage of leucine content, i.e., 15.0\%.

PSI-BLAST analyses of eight RPs were performed against non-redundant protein to determine the protein family, and top 4 best BLAST scores were obtained for each RP (Table 2). The sequence identity ranged between 57 and $100 \%$ in eight RPs, and the query coverage was in the range of $68-100 \%$.

\section{Physico-chemical properties of eight resistance proteins}

Physico-chemical parameters like molecular weight, pI, amino acid composition, estimated half-life, and instability index were performed in ExPASy ProtParam. The predicted molecular mass of eight RPs (RP1 to RP8) had $97.8 \mathrm{kDa}, \quad 168.3 \mathrm{kDa}, \quad 168.2 \mathrm{kDa}, 122.7 \mathrm{kDa}, 146.2 \mathrm{kDa}$, $116.4 \mathrm{kDa}, 117.4 \mathrm{kDa}$, and $102.5 \mathrm{kDa}$, respectively. The isoelectric points (pI) of eight RPs were found to be in the acidic range except for RP3 and RP8, which were slightly basic. The eight RPs showed high aliphatic index values (88.09-103.58), which indicated that the proteins are stable for a broad range of temperatures [22].

\section{Motifs and phylogenetic analysis}

The CDvist Web with HMMER3 against Pfam 30.0 and Interpro scan server was performed to identify the domains of eight resistance proteins. NBS-LRR proteins are the plant disease resistance proteins, which share similar sequences and domains [23]. The results of the CDvist analysis revealed that the NB-ARC domain was found in all the eight resistance proteins and the LRR domain was identified in RP1, RP4, RP5, RP6, and RP7 proteins. RXCC coiled-coil domain was identified in RP4, RP6, RP7, RP8 (Fig. 1a), and most of the NBS-LRR proteins contained some unknown domains, which were symbolized as X. Similarly, an Interpro scan server was used to predict the different domains: NB-ARC and LRR domain architectures were detected in all the eight resistance proteins. RX-CC domains are recognized in RP4, RP6, RP7, and RP8, and P-loop architecture was identified in RP1, RP2, RP3, RP4, RP6, and RP7 (Table 3).

The amino acid sequences for eight resistance proteins aligned separately to identify their sequence diversity 
Table 1 Amino acid composition of eight resistant proteins

\begin{tabular}{|c|c|c|c|c|c|c|c|c|}
\hline \multirow{2}{*}{$\begin{array}{l}\text { Amino acid } \\
\text { composition }\end{array}$} & \multicolumn{8}{|l|}{$\%$} \\
\hline & RP1 & RP2 & RP3 & RP4 & RP5 & RP6 & RP7 & RP8 \\
\hline Alanine (A) & 4.9 & 4.5 & 5.4 & 6.2 & 5.4 & 5.5 & 4.9 & 4.0 \\
\hline Arginine (R) & 5.3 & 4.1 & 6.1 & 5.9 & 5.3 & 5.5 & 6.4 & 7.9 \\
\hline Asparagine (N) & 3.4 & 4.5 & 4.1 & 3.8 & 4.2 & 4.0 & 4.5 & 3.3 \\
\hline Aspartic acid (D) & 5.8 & 5.5 & 4.5 & 4.9 & 7.0 & 6.0 & 5.2 & 6.3 \\
\hline Cysteine (C) & 3.3 & 2.3 & 2.5 & 2.7 & 1.9 & 2.6 & 2.4 & 2.8 \\
\hline Glutamine (Q) & 4.1 & 4.1 & 4.3 & 4.0 & 4.5 & 4.0 & 4.3 & 2.8 \\
\hline Glutamic acid (E) & 6.0 & 7.3 & 6.7 & 7.1 & 10.1 & 7.8 & 8.4 & 6.2 \\
\hline Glycine $(G)$ & 5.3 & 5.9 & 6.8 & 4.6 & 5.1 & 6.4 & 5.7 & 5.7 \\
\hline Histidine $(\mathrm{H})$ & 2.6 & 3.2 & 2.8 & 3.0 & 3.1 & 2.3 & 2.4 & 3.2 \\
\hline Isoleucine (I) & 5.3 & 6.0 & 5.2 & 5.4 & 6.0 & 5.8 & 5.9 & 6.2 \\
\hline Leucine (L) & 14.4 & 15.0 & 11.5 & 13.7 & 11.4 & 14.0 & 13.7 & 14.0 \\
\hline Lysine (K) & 5.6 & 7.5 & 6.7 & 5.8 & 9.7 & 6.5 & 6.3 & 4.5 \\
\hline Methionine (M) & 2.6 & 1.2 & 1.8 & 2.6 & 1.6 & 1.5 & 1.7 & 2.3 \\
\hline Phenylalanine (F) & 3.4 & 4.0 & 4.0 & 2.8 & 2.2 & 2.8 & 2.6 & 3.4 \\
\hline Proline (P) & 3.6 & 3.8 & 4.1 & 4.2 & 3.8 & 3.9 & 4.0 & 3.4 \\
\hline Serine (S) & 7.1 & 7.4 & 7.4 & 7.4 & 5.5 & 6.8 & 6.5 & 9.2 \\
\hline Threonine ( $\mathrm{T}$ ) & 5.0 & 5.0 & 4.8 & 4.9 & 4.2 & 4.3 & 4.7 & 3.8 \\
\hline Tryptophan (W) & 2.7 & 1.2 & 2.1 & 2.1 & 1.0 & 1.9 & 1.8 & 0.8 \\
\hline Tyrosine $(Y)$ & 2.8 & 2.0 & 3.1 & 2.2 & 3.0 & 1.9 & 2.1 & 3.0 \\
\hline Valine (V) & 7.1 & 5.6 & 6.2 & 6.7 & 5.2 & 6.4 & 6.3 & 7.2 \\
\hline
\end{tabular}

Values in bold indicate that all resistant proteins are rich in leucine residues confirming the presence of leucine-rich repeats

and phylogenetic relationships (Fig. 1b) revealed two distinct clades. RP5 and Pita branched out from RP4 and another cluster formed by RP3 and RP8 and they branched out from Pik2. In the other clade, RP1 and RP2 of resistant cultivar branched out from RP6 and RP7 and clustered out with reported blast resistance proteins.

\section{Protein modeling}

SWISS-MODEL servers adopted to model the eight resistance proteins (Table 4) revealed that eight RPs share only $12.84-18.85 \%$ sequence identity and $26-65 \%$ query coverage with root-mean-square deviation (RMSD) of $1.74 \AA-4.50 \AA$. Further, the top four templates were selected for each RP from the PSI-BLAST program to build the best target model by using Modeller 9.22 server. Template models were taken from Protein Data Bank. The best target models were selected based on the lowest DOPE (discrete optimized protein energy) for each RP in Modeller which led to our secondary structure predictions. These PDB files of eight resistance proteins were visualized by UCSF Chimera software (Fig. 2).

\section{Secondary structure and function prediction}

The secondary structure predictions from the ProFunc server showed predominant alpha-helical coiled structures in all eight RPs (Fig. 3). In the RaptorX property prediction of eight RPs showed that $26-41 \%$ of residues are involved in the $\alpha$-helices structure formation, $9-14 \%$ residues are arranged in $\beta$-strands, and $48-60 \%$ of the residues occur as coils. The solvent accesses of exposed, medium, and buried regions of eight RPs were found to be in the range of $26-31 \%, 38-48 \%$, and $25-$ $30 \%$ in RaptorX prediction function.

The COACH server based on the I-TASSER structure prediction used to predict the active sites of the eight resistance proteins (Fig. 4) revealed that the ADP binding site of RP1 was mainly composed of the amino acid numbers V115, R117, T118, F119, R121, G145, G146, G148, K149, T150, and T151. The important active site residues having binding activity for LMB (Leptomycin B) of RP2 were C181, H188, K192, P195, K198, and R201. The amino acid residues with a binding site for 2S2(2S)-2-(1H-INDOL-3-YL) hexanoic acid were found to be D1366, R1368, T1388, V1389, S1390, R1427, K1429, I1430, D1465, I1466, and A1467 in RP3. The amino acid residues of RP4 with binding sites for ADP were P247, L249, V250, G251, I254, G282, G283, V284, G285, K286, T287, T288, P446, L447, K450, E556, and H570 [24]. L1254 and D1258 amino acid residues were involved in the binding site for HEM in RP5. The amino acid 
Table 2 Sequence identity and similarity between BCRP and available templates

\begin{tabular}{|c|c|c|c|c|c|}
\hline & Name & Query cover (\%) & Identity (\%) & Total score & Accession \\
\hline \multirow[t]{4}{*}{ RP1 } & Hypothetical protein Osl_05235 & 100 & 100 & 1769 & EAY77261.1 \\
\hline & NBS-LRR like resistance protein & 100 & 99 & 1753 & ALO70091.1 \\
\hline & Hypothetical protein OsJ_04789 & 98 & 99 & 1749 & EEE56018.1 \\
\hline & Putative blight resistance protein RGA1 & 100 & 97 & 1727 & BAD87860.1 \\
\hline \multirow[t]{4}{*}{ RP2 } & Predicted: disease RP RGA2-like & 99 & 100 & 3056 & XP_015645850.1 \\
\hline & Hypothetical protein Osl_24856 & 99 & 99 & 3054 & EAZ02738.1 \\
\hline & NBS-LRR-like resistance protein & 99 & 99 & 3030 & ALO70120.1 \\
\hline & NBS-LRR-like resistance protein & 99 & 99 & 3029 & ALO70121.1 \\
\hline \multirow[t]{4}{*}{ RP3 } & Os09g0314100 [Oryza sativa japonica Group] & 99 & 95 & 2926 & BAH94489.1 \\
\hline & Hypothetical protein Osj_28823 & 99 & 92 & 2793 & EEC84327.1 \\
\hline & Hypothetical protein OsJ_28823 & 90 & 99 & 2757 & EEE69434.1 \\
\hline & Os09g0314200 [Oryza sativa Japonica Group] & 68 & 98 & 2075 & BAT07400.1 \\
\hline \multirow[t]{4}{*}{ RP4 } & NB-ARC domain, putative & 99 & 100 & 2234 & AAX95985.1 \\
\hline & Predicted: putative disease RP RGA3 & 91 & 100 & 2044 & XP_015615198.1 \\
\hline & Predicted: putative disease RP RGA4 & 91 & 84 & 1670 & XP_015697828.1 \\
\hline & Predicted: uncharacterized protein & 91 & 58 & 1092 & XP_014757772.1 \\
\hline \multirow[t]{4}{*}{ RP5 } & Leucine rich repeat family protein, expressed & 99 & 100 & 2624 & ABA94704.2 \\
\hline & Os11g0598500 [Oryza sativa Japonica Group] & 96 & 97 & 2522 & BAF28579.1 \\
\hline & Predicted: uncharacterized protein & 96 & 95 & 2447 & XP_015615610.1 \\
\hline & Hypothetical protein OsJ_34447 & 71 & 100 & 1865 & EEE52373.1 \\
\hline \multirow[t]{4}{*}{ RP6 } & Predicted: Putative disease RPRGA4 & 99 & 100 & 2118 & XP_015617680.1 \\
\hline & Os11g0763600 [Oryza sativa japonica Group] & 94 & 99 & 2011 & BAH95435.1 \\
\hline & NBS-LRR-like protein & 99 & 93 & 1901 & AAK93796.1 \\
\hline & Predicted: Putative disease RPRGA4 & 99 & 90 & 1826 & XP_015617526.1 \\
\hline \multirow[t]{4}{*}{ RP7 } & Predicted: Putative disease RPRGA3 & 99 & 100 & 2122 & XP_015616937.1 \\
\hline & Os11g0676050 [Oryza sativa japonica Group] & 99 & 90 & 3133 & BAH95438.1 \\
\hline & Predicted: Putative disease RPRGA4 & 99 & 90 & 1790 & XP_015617526.1 \\
\hline & Predicted: Putative disease RPRGA4 & 99 & 84 & 1709 & XP_015617680.1 \\
\hline \multirow[t]{4}{*}{ RP8 } & NB-ARC domain containing protein & 99 & 100 & 1845 & ABA96074.2 \\
\hline & Hypothetical protein OsJ_35504 & 86 & 96 & 1503 & EAZ19911.1 \\
\hline & Predicted: disease resistance RPP13-like protein 3 & 95 & 60 & 1009 & XP_010238635.1 \\
\hline & Predicted: disease resistance RPP13-like protein 3 & 99 & 57 & 998 & XP_015698835.1 \\
\hline
\end{tabular}

$R P$ resistance protein

residues V849, K851, D911, L912, V913, K934, F936, 1937, F977, V978, and N979 were the binding site residues for $2 \mathrm{~S} 2$ - (2S)-2-(1H-INDOL-3-YL) hexanoic acid in RP6. The ligand-binding site residues for RP7 were T208 and L279 involved in the ligand MG binding site. The ligandbinding site for RP8 was L136, E138, V153, Y156, A157, N158, G189, L190, G191, K192, T193, T194, L321, L329, P360, L361, and M364 involved in the ADP binding site (Table 5) [25].

PROFUNC predicts the cellular component, biological process, and biochemical function of eight resistance proteins, and the results are depicted in Table 6 . The
PROFUNC predicts the probable functions based on the 3D structure of the target protein [26]. The eight resistance proteins showed scores in the cellular, biological, and biochemical functions. The cellular component scores ranged from 1.68-38.14, biological process ranged between 3.73-40.39, and biochemical function were in the range of 13.61-49.87.

\section{SuperPose}

The root means square deviation (RMSD) that measures the distance between corresponding residues and accurate models should have $<2.0 \AA$ value [27]. RMSD 

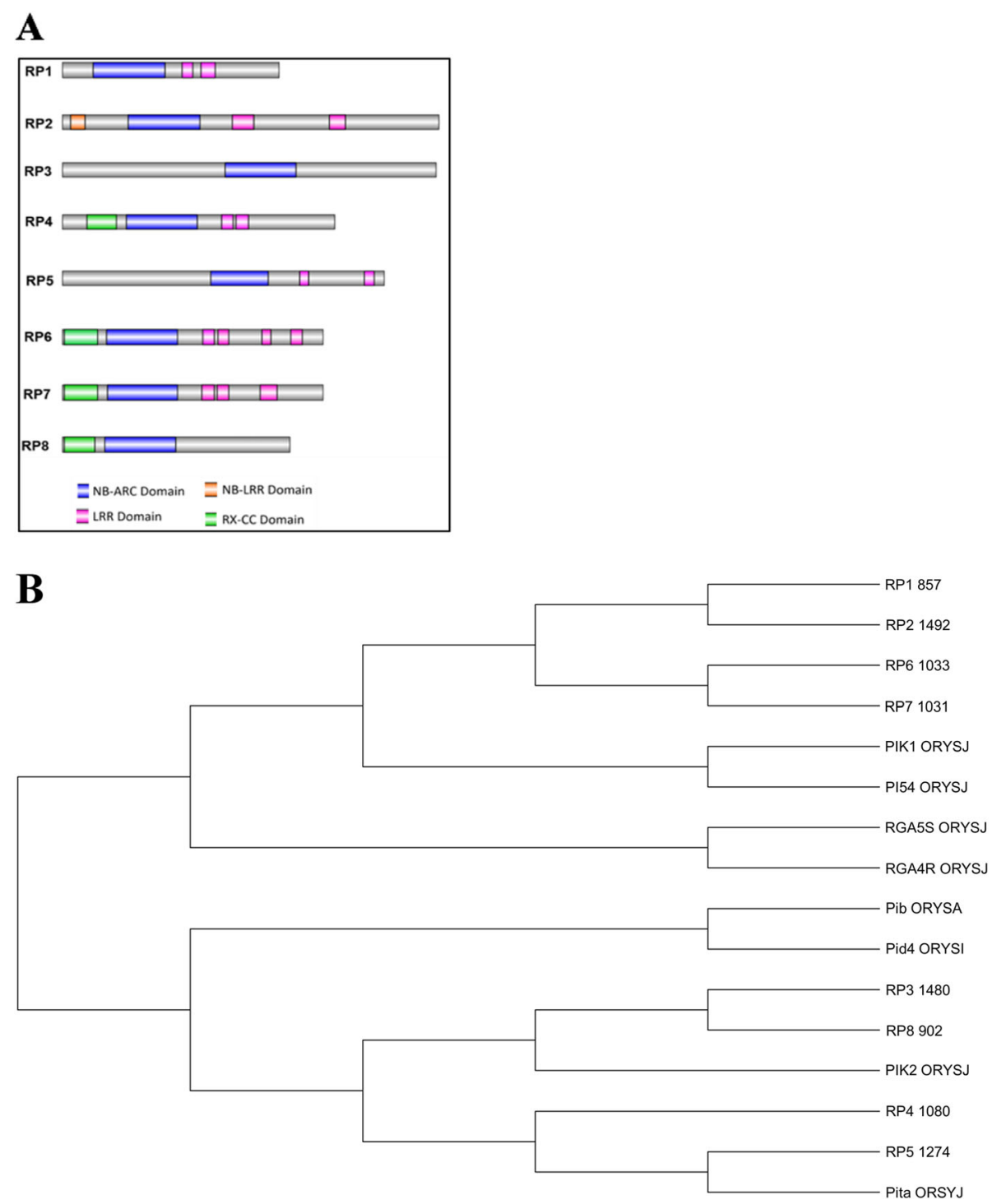

Fig. 1 a Domain architecture of eight resistance proteins predicted by the Cdvist web server tool and $\mathbf{b}$ phylogenetic relationship among the eight rice blast resistance protein trees generated using the neighbor-joining method by MEGA.7 software with bootstrap value 1000 replications

calculates how much the resistance protein deviates from each other. The eight RPs superimposed each other separately using all the permutations and combinations (Table 7) showed that RP5 was superimposed with RP8 with the least RMSD value (1.2 ̊). The RP1, RP2, RP3, RP4, RP6, and RP7 were having identical three-dimensional structures and having an RMSD value ranging between 1.45 and $2.22 \AA$. The superimposed structures of all eight-resistance protein models indicate that the overall conformations are very similar except RP5.

\section{Structure validation}

Ramachandran plot showed the distribution of $\phi$ and $\psi$ angle in the eight resistance protein models within the limits (Fig. 5). Ramachandran plot statistics displayed that 647 amino acid residues (83.1\%) are in the favored region, 99 amino acid residues (12.7\%) are in the additional allowed region, and 24 amino acid residues (3.1\%) are in the generously allowed region, while only nine amino acid residues (1.2\%) are in the disallowed region in RP1. RP2 showed that 1323 amino acid residues (98.4\%) are in the allowed region and 21 amino acid residues $(1.6 \%)$ are in the disallowed region. RP3 displayed 1223 amino acid residues (98.3\%) are in the allowed region and 21 (1.7\%) in the disallowed region. RP4 showed 966 amino acid residues (98.2\%) are in the allowed and 17 amino acid residues (1.7\%) in the disallowed region. RP5 showed 1101 amino acid residues (94.9\%) is allowed and 58 amino acid residues (5.8\%) in the disallowed region. RP6 showed 908 amino acid residues (98.0\%) in 
Table 3 CDvist and Interpro Scan online tools performed for the identification of different domains (or motif analysis) for eight resistance proteins

\begin{tabular}{|c|c|c|c|c|}
\hline \multirow[t]{2}{*}{ Protein } & \multicolumn{2}{|l|}{ CDvist } & \multicolumn{2}{|c|}{ Interpro Scan } \\
\hline & Domain & Region & Domain & Region \\
\hline \multirow[t]{3}{*}{$\mathrm{RP1}$} & NB-ARC & $124-406$ & NB-ARC & $133-401$ \\
\hline & LRR4 & $476-519$ & LRR & $550-620$ \\
\hline & LRR8 & $549-606$ & P-loop & $137-377$ \\
\hline \multirow[t]{4}{*}{$\mathrm{RP2}$} & - & - & NB-ARC & $277-536$ \\
\hline & & & P-loop & $242-515$ \\
\hline & & & LRR & 577-968, \\
\hline & & & & $978-1178$ \\
\hline \multirow[t]{3}{*}{ RP3 } & NB-ARC & 644-925 & NB-ARC & $656-922$ \\
\hline & & & P-loop & $608-896$ \\
\hline & & & LRR & $1053-1450$ \\
\hline \multirow[t]{4}{*}{ RP4 } & $\mathrm{RX}-\mathrm{CC}$ & $99-217$ & $\mathrm{RX}-\mathrm{CC}$ & $98-216$ \\
\hline & NB-ARC & $254-535$ & NB-ARC & $265-534$ \\
\hline & LRR8 & $632-678$ & P-loop & $255-506$ \\
\hline & LRR4 & 689-736 & LRR & 619-937, 942-1056 \\
\hline \multirow[t]{3}{*}{ RP5 } & NB-ARC & $587-815$ & NB-ARC & $598-811$ \\
\hline & LRR4 & $939-975,1197-1234$ & LRR & $872-1068$ \\
\hline & & & & 1069-1232 \\
\hline \multirow[t]{5}{*}{ RP6 } & $\mathrm{RX}-\mathrm{CC}$ & 10-139 & $R X-C C$ & $9-138$ \\
\hline & NB-ARC & $177-457$ & NB-ARC & $187-455$ \\
\hline & LRR8 & $555-604$ & P-loop & $179-428$ \\
\hline & LRR4 & $615-660,791-826$ & LRR & $516-864$ \\
\hline & & $905-952$ & & $895-1009$ \\
\hline \multirow[t]{4}{*}{ RP7 } & $\mathrm{RX}-\mathrm{CC}$ & 10-139 & $\mathrm{RX}-\mathrm{CC}$ & $9-138$ \\
\hline & NB-ARC & $178-456$ & NB-ARC & $187-454$ \\
\hline & LRR8 & $552-603$ & P-loop & $180-427$ \\
\hline & LRR4 & $614-659,785-852$ & LRR & $513-862,894-1018$ \\
\hline \multirow[t]{3}{*}{ RP8 } & $\mathrm{RX}-\mathrm{CC}$ & $8-130$ & $\mathrm{RX}-\mathrm{CC}$ & $7-129$ \\
\hline & NB-ARC & $169-449$ & NB-ARC & $183-447$ \\
\hline & & & LRR & $662-683,723-745,750-771$ \\
\hline
\end{tabular}

the allowed region and 17 amino acid residues (1.8\%) in the disallowed region. RP7 identified 905 amino acid residues (97.4\%) is allowed and 24 amino acid residues (2.6\%) in the disallowed region. RP showed 804 amino acid residues (98.3\%) in the allowed and14 amino acid residue $(1.7 \%)$ in the disallowed region. Ramachandran plot of eight resistance proteins confirmed that the model structures are following dihedral angles of Ramachandran plot occupied favorable positions [12].

\section{Discussion}

In rice plants, many resistance genes are mostly polymorphic [28] which are involved to initiate the cascade signaling to trigger the defense response in rice plants. Understanding the differential gene expression of resistance genes and their action may give new insights to study the differential transcriptional regulation in rice plant and model the blast resistance protein structures which are expressed during $M$. oryzae infection.

Transcriptomic studies carried out during the present investigation revealed some common transcripts for both BR2655 and HR12. We also observed many of the transcripts are unique to the resistant cultivar, viz., BR2655, and susceptible cultivar HR12 separately. A similar difference in the transcriptomic profiles was observed in Italian rice varieties Gigante Vercelli and Vialone Nano cultivars of rice [29]. Many researchers have carried out previously transcriptomic studies in rice cultivars inoculated with different pathogens [30, 31]. Many such studies are carried out in different plants like tomato, banana, and maize [32, 33]. 
Table 4 Homology modeling of eight resistance proteins

\begin{tabular}{|c|c|c|c|c|c|c|c|c|c|c|c|}
\hline \multirow[t]{3}{*}{ Protein } & \multicolumn{4}{|c|}{ Swiss Model } & \multicolumn{4}{|c|}{ I-TASSER } & \multicolumn{3}{|l|}{ PHYRE2 } \\
\hline & PDB ID & Identity & Query & $\overline{\text { RMSD }}$ & PDB ID & Identity & Query & $\overline{\text { RMSD }}$ & PDB ID & Identity & Query \\
\hline & & $(\%)$ & Coverage & & & $(\%)$ & Coverage & & & $(\%)$ & Coverage \\
\hline \multirow[t]{4}{*}{ RP1 } & 4kxf.1.A & 16.67 & 0.47 & $3.20 \AA$ & $3 s f z A$ & 0.11 & 0.84 & 2.76 & c2a5yB & 14.00 & 48.00 \\
\hline & 4kxf.2.A & 16.67 & 0.47 & $3.20 \AA$ & $1 z 6 t B$ & 0.13 & 0.50 & 2.63 & c1vt4K & 18.00 & 60.00 \\
\hline & 4kxf.3.A & 16.67 & 0.47 & $3.20 \AA$ & 3izaA & 0.05 & 0.61 & 6.50 & C1vt4J & 18.00 & 60.00 \\
\hline & $4 \mathrm{kxf} .4 . \mathrm{A}$ & 16.67 & 0.47 & $3.20 \AA$ & $1 \mathrm{vt} 4 \mathrm{l}$ & 0.07 & 0.62 & 7.30 & c3iz8E & 18.00 & 60.00 \\
\hline \multirow[t]{4}{*}{ RP2 } & $4 \mathrm{mn} 8.1 . \mathrm{A}$ & 17.73 & 0.45 & $3.06 \AA$ & 3javA & 0.09 & 0.97 & 1.70 & c2a5yB & 14.00 & 36.00 \\
\hline & 4mn8.1.A & 17.76 & 0.45 & $3.06 \AA$ & $5 \mathrm{hb} 4 \mathrm{~B}$ & 0.04 & 0.47 & 9.25 & clvt4P & 14.00 & 44.00 \\
\hline & 3jbl.1.A & 15.66 & 0.42 & $4.50 \AA$ & 3opbA & 0.04 & 0.37 & 6.85 & clvt4L & 14.00 & 44.00 \\
\hline & 5gr8.1.A & 16.64 & 0.42 & $2.59 \AA$ & $5 f y m A$ & 0.03 & 0.44 & 9.68 & clvt4K & 14.00 & 44.00 \\
\hline \multirow[t]{4}{*}{ RP3 } & 4m9y.1.B & 17.08 & 0.28 & $4.20 \AA$ & $6 \mathrm{~b} 5 \mathrm{bA}$ & 0.11 & 0.78 & 2.43 & c2a5yB & 17.00 & 30.00 \\
\hline & 2a5y.1.C & 17.08 & 0.28 & $2.60 \AA$ & $4 \mathrm{kxfK}$ & 0.08 & 0.45 & 5.21 & c3iz8A & 19.00 & 41.00 \\
\hline & 2a5y.1.B & 17.08 & 0.28 & $2.60 \AA$ & $1 \mathrm{vt} 4 \mathrm{I}$ & 0.04 & 0.49 & 8.96 & c3iz8E & 19.00 & 41.00 \\
\hline & 3lar.1.B & 17.08 & 0.28 & $3.90 \AA$ & 3izaA & 0.05 & 0.45 & 8.38 & clvt4M & 19.00 & 41.00 \\
\hline \multirow[t]{4}{*}{ RP4 } & 5gs0.1.A & 16.06 & 0.26 & $3.28 \AA$ & $1 z 6 t B$ & 0.15 & 0.52 & 1.20 & c2a5yB & 15.00 & 42.00 \\
\hline & 3ulv.1.A & 16.33 & 0.26 & $3.52 \AA$ & $3 s f z A$ & 0.09 & 0.43 & 1.91 & c1vt4N & 15.00 & 51.00 \\
\hline & 1ziw.1.A & 16.14 & 0.26 & $2.10 \AA$ & $3 v k g A$ & 0.05 & 0.56 & 9.47 & c3iz8F & 15.00 & 51.00 \\
\hline & 4lsa.1.A & 17.82 & 0.27 & $3.30 \AA$ & 4ai6A & 0.03 & 0.50 & 9.02 & c3iz8A & 15.00 & 51.00 \\
\hline \multirow[t]{4}{*}{ RP5 } & 4kxf.1.A & 12.84 & 0.46 & $3.20 \AA$ & $6 b 5 b A$ & 0.08 & 0.86 & 2.01 & c2a5yB & 11.00 & 34.00 \\
\hline & 4kxf.2.A & 12.84 & 0.46 & $3.20 \AA$ & $4 \mathrm{kxfK}$ & 0.06 & 0.51 & 5.38 & c3iz8F & 15.00 & 34.00 \\
\hline & 4kxf.3.A & 12.84 & 0.46 & $3.20 \AA$ & $1 \mathrm{vt} 4 \mathrm{I}$ & 0.04 & 0.55 & 8.42 & c3iz8G & 15.00 & 34.00 \\
\hline & 4kxf.4.A & 12.84 & 0.46 & $3.20 \AA$ & 3izaA & 0.05 & 0.50 & 8.19 & c3iz8A & 15.00 & 34.00 \\
\hline \multirow[t]{4}{*}{ RP6 } & 3jbl.1.A & 15.47 & 0.64 & $4.50 \AA$ & $6 \mathrm{~b} 5 \mathrm{bA}$ & 0.12 & 0.86 & 2.06 & c2a5yB & 15.00 & 44.00 \\
\hline & 5gs0.1.A & 14.81 & 0.45 & $3.28 \AA$ & $4 \mathrm{kxfK}$ & 0.08 & 0.55 & 4.93 & c3iz8D & 19.00 & 43.00 \\
\hline & $4 \mathrm{mn} 8.1 . \mathrm{A}$ & 18.00 & 0.44 & $3.06 \AA$ & $1 \mathrm{vt} 4 \mathrm{l}$ & 0.07 & 0.59 & 8.34 & c1vt4P & 19.00 & 43.00 \\
\hline & 4z0c.1.A & 18.85 & 0.44 & $2.30 \AA$ & $5 \times 60 C$ & 0.04 & 0.58 & 8.30 & c3iz8c & 19.00 & 43.00 \\
\hline \multirow[t]{4}{*}{ RP7 } & 3jbl.1.A & 14.33 & 0.65 & $4.50 \AA$ & $6 b 5 b A$ & 0.12 & 0.85 & 2.27 & c2a5yB & 15.00 & 44.00 \\
\hline & 5ixo.1.A & 16.89 & 0.42 & $1.74 \AA$ & $4 \mathrm{kxfK}$ & 0.08 & 0.55 & 5.36 & c3iz8G & 17.00 & 43.00 \\
\hline & 4lsx.1.A & 17.54 & 0.43 & $3.30 \AA$ & $1 \mathrm{vt} 4 \mathrm{I}$ & 0.07 & 0.58 & 8.26 & c3iz8F & 17.00 & 43.00 \\
\hline & 4lsa.1.A & 17.54 & 0.43 & $2.50 \AA$ & $5 \times 60 C$ & 0.04 & 0.59 & 8.40 & c1vt4O & 17.00 & 43.00 \\
\hline \multirow[t]{4}{*}{ RP8 } & 3jbl.1.A & 15.02 & 0.67 & $4.50 \AA$ & $4 \mathrm{kxfk}$ & 0.13 & 0.82 & 2.47 & c2a5yB & 15.00 & 50.00 \\
\hline & 4m9y.1.B & 16.38 & 0.45 & $4.20 \AA$ & $6 \mathrm{~b} 5 \mathrm{bA}$ & 0.05 & 0.62 & 5.46 & c3iz8B & 17.00 & 49.00 \\
\hline & 2a5Y.1.C & 16.38 & 0.45 & $2.60 \AA$ & 5irlA & 0.08 & 0.58 & 5.85 & c1vt4L & 17.00 & 49.00 \\
\hline & 2a5Y.1.B & 16.38 & 0.45 & $2.60 \AA$ & $5 \mathrm{~h} 64 \mathrm{~A}$ & 0.05 & 0.67 & 8.46 & $3 i z 8 F$ & 17.00 & 49.00 \\
\hline
\end{tabular}

We observed the difference in the response of pathogenesis and gene expression profiling in BR2655 and HR12 rice cultivars during infection by $M$. oryzae. When the transcripts of cultivars are analyzed, it is important to analyze different categories of transcripts expressed, viz., only in resistant, both in resistant and susceptible and only in susceptible cultivars. Accordingly, we identified the $\mathrm{R}$ genes which are expressed exclusively in the resistance cultivar BR2655 which may play a decisive role in conferring resistance to the plants. The $R$ genes which are expressed in both may be responsible for initiating the defensive mechanism. The $r$ genes which are expressed exclusively in susceptible cultivars may not be effective in overcoming a specific pathogen like $M$. oryzae due to change in the cascade of multiple signaling pathways resulting in the virulence of a given pathogen.

In the present study, we thus have shortlisted eight blast resistance transcripts, two each exclusively from BR2655 and HR12 and four common to both the rice cultivars, and their protein sequences were retrieved for further computational analysis and characterization. Resistance proteins are broadly classified into eight groups based on their different conserved 


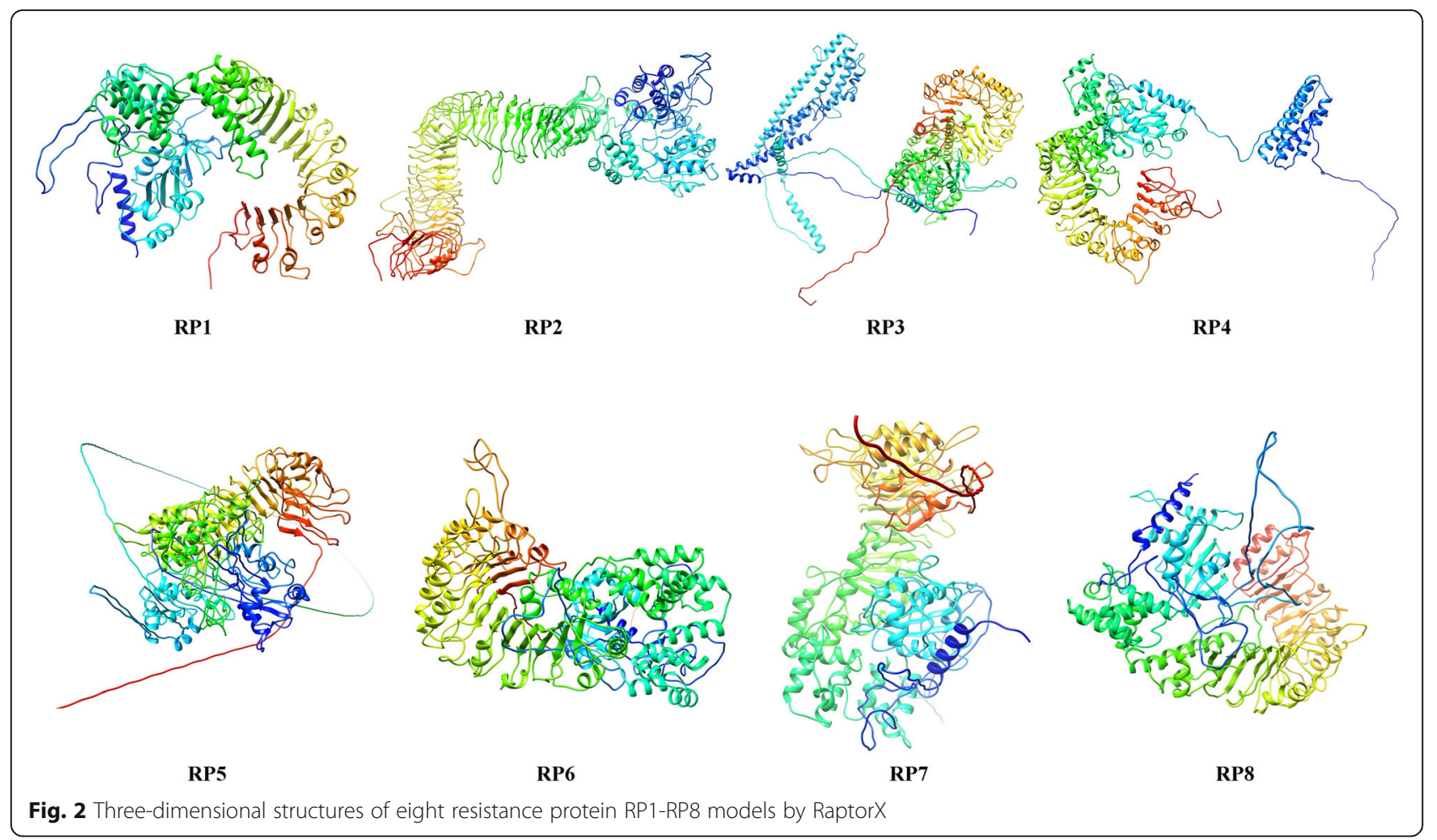

domain organization and secondary structures. These resistance proteins are the key players in the plant defense signaling mechanisms [4]. All the shortlisted resistance proteins bearing NBS were observed, and physiochemical properties of all the RP proteins were analyzed in the current study.

\section{Motifs and phylogenetic tree}

The eight resistance proteins encode nucleotide-binding site leucine-rich repeats (NBS-LRR) involved in the defense mechanism which share similar sequences and domains [23]. NBS-LRR domains investigated during the

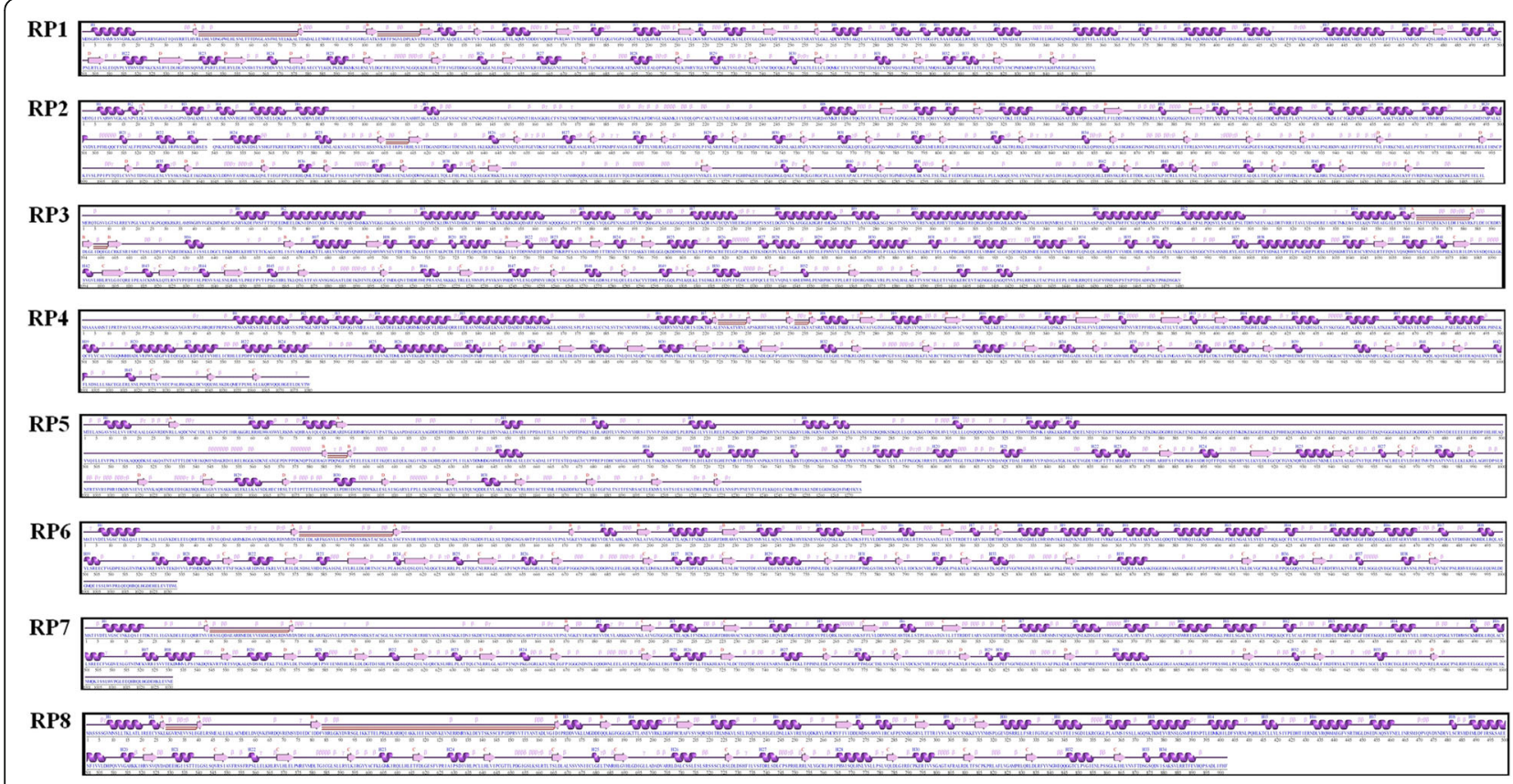

Fig. 3 Secondary structures of eight resistance proteins by ProFunc server 


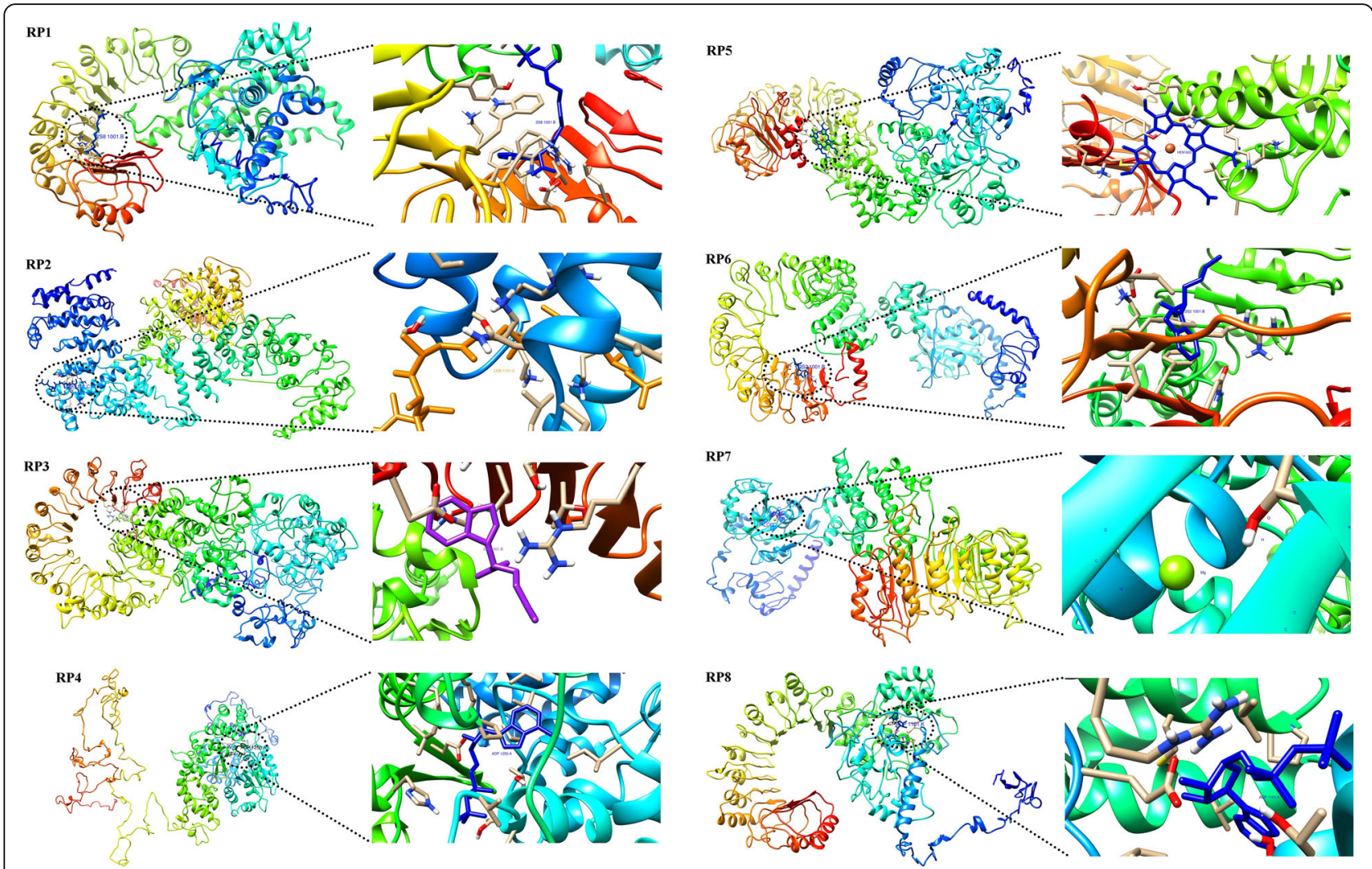

Fig. 4 Binding sites of RP1, RP2, RP3, RP4, RP5, RP6, RP7, and RP8 resistance proteins by using the COACH server based on the I-TASSER structure prediction

current study and most of the domains reported by earlier workers contained some unknown domains, which were symbolized as X [34].. Coiled-coil amino acid sequences of resistance proteins are involved in the signal transduction in many cell processes [35]. NB-ARC and LRR domain architectures were detected in all the eight resistance proteins. These domains play an important role in plant resistance gene inactivation of downstream effectors [36]. The conserved amino acid residues of RP1 was involved in the binding of ADP and reported to be involved in signal transduction [37]. RP2 involves in the binding activity for LMB (Leptomycin B), and RP4 conserved amino acid residues were involved in the binding site for 2S2 - (2S)-2(1H-INDOL-3-YL) hexanoic acid, having binding sites for ADP [37] and RP8 conserved amino acid residues in the binding site residues for 2S2-(2S)-2-(1H- INDOL-3-YL) hexanoic acid, which acts as ADP binding site [38]. The results revealed that these eight resistance proteins might involve in the transmembrane transport of metal ions.

A phylogenetic tree generated based on the amino acid sequences of these 8 resistance proteins is divided into two groups. A similar analysis was reported for resistance proteins in verticillium wilt-resistant cotton plants [32]. The eight resistant proteins are having a structural and functional relationship with each other indicating that these proteins are well conserved and evolved in the same family of their evolutionary history. Similar studies were also reported in Arabidopsis during pathogen attack Pseudomonas syringae [39].

The physico-chemical properties of eight resistance proteins and their amino acid composition revealed the existence of high-frequency leucine-rich repeats. They are involved in hydrophobic interactions and conformational stability of the RP proteins [40]. The aliphatic index of hypothetical eight RPs revealed that they are stable even at high temperatures. These RPs have hydrophilic amino acids which are capable of interacting with surrounding water molecules intracellularly [41].

\section{Homology modeling}

SWISS-Model and Modeller servers were used to build the three-dimensional structures of eight RPs. The templates showed similarity or identity for the eight resistance proteins, and these template models are associated with cell death protein 4 (PDB ID: 3lqr.1.A, PDB ID: 2a5y.1.B), which are localized to the nucleus in proliferating cells [42].

Recently, the cryo-electron microscopy structure of NBS-LRR, such as the wheel-like pentameric ZAR1 resistosome, has been revealed in Arbidopsis thaliana [43]. Similar template structures were used for modeling in the current study, and it helped us to decipher the 
Table 5 Ligand binding site predictions of eight resistance proteins

\begin{tabular}{|c|c|c|c|c|c|c|}
\hline Protein & Rank & C-score & Cluster size & PDB hit & Ligand name & Ligand binding site residues \\
\hline \multirow[t]{5}{*}{ RP1 } & 1 & 0.09 & 4 & $3 s f z A$ & ADP & $115,117-119,121,145,146,148-151$ \\
\hline & 2 & 0.07 & 4 & $4 \mathrm{~m} 9 \mathrm{sC}$ & PEPTIDE & $360,363,364,371,372,375,455,456,459$ \\
\hline & 3 & 0.05 & 2 & 5 aorB & MG & 150,216 \\
\hline & 4 & 0.04 & 2 & 3shfa & GBL & $378,379,453,460$ \\
\hline & 5 & 0.02 & 1 & 5hhjA & GLY & 271,274 \\
\hline \multirow[t]{5}{*}{ RP2 } & 1 & 0.04 & 3 & $4 \mathrm{hb} 4 \mathrm{C}$ & LMB & 181, 188, 192, 195, 198, 201 \\
\hline & 2 & 0.04 & 3 & $3 a n 2 E$ & Nuc. Acid & $828,829,830$ \\
\hline & 3 & 0.03 & 2 & $2 z 4 r A$ & MG & $295,365,366$ \\
\hline & 4 & 0.03 & 2 & $2 \mathrm{a} 5 \mathrm{yB}$ & ATP & $255,258,290-296,397,425,429,457,458$ \\
\hline & 5 & 0.03 & 2 & 4hazC & LBF & $182,189,192,201,204$ \\
\hline \multirow[t]{5}{*}{ RP3 } & 1 & 0.09 & 6 & $2 \mathrm{a} 5 \mathrm{yB}$ & 252 & $1366,1368,1388-1390,1427,1429,1430,1465-1467$ \\
\hline & 2 & 0.09 & 6 & $3 c 60 B$ & ATP & $621,624,671-677,779,806,810,837,838,841,868$ \\
\hline & 3 & 0.03 & 2 & 5d0fA & MTT & $939,942,943,946$ \\
\hline & 4 & 0.02 & 1 & $2 \mathrm{a} 5 \mathrm{yC}$ & MG & 676,748 \\
\hline & 5 & 0.02 & 1 & N/A & N/A & 884,939 \\
\hline \multirow[t]{5}{*}{ RP4 } & 1 & 0.21 & 7 & $3 s f z A$ & ADP & $247,249-251,254,282-288,446,447,450,556,570$ \\
\hline & 2 & 0.05 & 2 & $4 \mathrm{~m} 9 \mathrm{zA}$ & MG & $287,359,360,386$ \\
\hline & 3 & 0.05 & 2 & 2qbyA & MG & $287,359,447$ \\
\hline & 4 & 0.03 & 1 & N/A & N/A & $844,866,870,872,874,926,933,935,941,945,947$ \\
\hline & 5 & 0.02 & 1 & N/A & N/A & $621,625,628,665,669$ \\
\hline \multirow[t]{5}{*}{ RP5 } & 1 & 0.07 & 5 & $1 \mathrm{~m} 7 \mathrm{sA}$ & HEM & 1254,1258 \\
\hline & 2 & 0.04 & 3 & $3 \mathrm{cr} 3 \mathrm{~A}$ & MG & 638,639 \\
\hline & 3 & 0.03 & 2 & 4rkuG & CLA & 773,776 \\
\hline & 4 & 0.03 & 2 & $4 \mathrm{hzcG}$ & MG & 760,762 \\
\hline & 5 & 0.02 & 1 & N/A & N/A & 1142, 1145, 1154, 1156, 1160, 1164-1168, 1173, 1176 \\
\hline \multirow[t]{5}{*}{ RP6 } & 1 & 0.08 & 4 & $3 c 60 B$ & $2 \$ 2$ & $849,851,911-913,934,936,937,977,978,979$ \\
\hline & 2 & 0.06 & 3 & $2 \mathrm{p} 1 \mathrm{nB}$ & CFA & $728,730,764,765,766,789,790,812-814$ \\
\hline & 3 & 0.03 & 1 & $1 v+4 \mid$ & MG & 208,279 \\
\hline & 4 & 0.02 & 1 & $1 \mathrm{koiA}$ & NO & 568,571 \\
\hline & 5 & 0.02 & 1 & $3 W 3 A$ & L07 & $704,733,769$ \\
\hline \multirow[t]{5}{*}{ RP7 } & 1 & 0.10 & 5 & $1 \mathrm{vt} 4 \mathrm{l}$ & MG & 208,279 \\
\hline & 2 & 0.08 & 5 & $2 \mathrm{a} 5 \mathrm{yB}$ & ATP & $168,171,203-209,309,336,340,367,368,371,399$ \\
\hline & 3 & 0.06 & 4 & $3 \mathrm{c} 60 \mathrm{~B}$ & 252 & $811,813,848-850,909,911,936,937,938$ \\
\hline & 4 & 0.05 & 3 & $30 g k B$ & OGK & $727,763-765,788,790,813,848,913,935$ \\
\hline & 5 & 0.05 & 3 & $2 \mathrm{p} 1 \mathrm{pB}$ & IAC & $911,936-938,977,978,997,998,999,1029$ \\
\hline \multirow[t]{5}{*}{ RP8 } & 1 & 0.23 & 11 & $4 \mathrm{kxfK}$ & ADP & $136,138,153,156-158,189-194,321,329,360,361,364$ \\
\hline & 2 & 0.08 & 4 & 3u60E & MG & $193,270,271,361$ \\
\hline & 3 & 0.04 & 2 & $3+6 q A$ & MAN & 616,641 \\
\hline & 4 & 0.02 & 1 & $3 w 3 n B$ & $\mathrm{RX} 8$ & $571,573,574,597,599,623$ \\
\hline & 5 & 0.02 & 1 & $3 \mathrm{~b} 2 \mathrm{dA}$ & MAN & 662,687 \\
\hline
\end{tabular}

binding site variations that may occur in different resistance proteins. RP2 was found to be similar to LRR receptor-like serine/threonine-protein kinase FLS2 (PDB ID: 4 mn8.1.A) which functions as a pattern recognition receptor [37]. RP4 resembles Toll-like receptor 3 (PDB ID: 5gs0.1.A) which functions as pathogen recognition and activation of innate immunity protein [44], RP5 NLR family CARD Domain-containing Protein 4 (PDB 
Table 6 Gene Ontology of eight resistance proteins

\begin{tabular}{|c|c|c|c|c|c|c|c|c|}
\hline \multirow[t]{2}{*}{ Functions } & RP1 & RP2 & RP3 & RP4 & RP5 & RP6 & RP7 & RP8 \\
\hline & \multicolumn{8}{|l|}{ Score } \\
\hline \multicolumn{9}{|l|}{ Cellular component } \\
\hline Cell & 22.79 & 16.55 & 7.89 & 22.18 & 4.83 & 19.57 & 38.14 & 10.12 \\
\hline Cell Part & 22.79 & 16.55 & 7.89 & 22.18 & 4.83 & 19.57 & 38.14 & 10.12 \\
\hline Membrane & 17.87 & - & - & 17.53 & 3.73 & 12.30 & 25.02 & 5.43 \\
\hline Integral to membrane & 9.17 & - & - & - & 1.68 & - & 17.30 & - \\
\hline Membrane part & - & - & - & 8.29 & - & - & - & - \\
\hline Intracellular & - & 9.54 & 4.08 & - & - & - & - & - \\
\hline Intracellular part & - & 9.54 & 4.08 & - & - & - & - & - \\
\hline Plasma membrane & - & - & - & - & - & - & - & - \\
\hline Cytoplasm & - & - & - & - & - & - & - & 4.90 \\
\hline \multicolumn{9}{|l|}{ Biological process } \\
\hline Cellular Process & 33.37 & 18.60 & 12.35 & 32.50 & 4.83 & 22.17 & 40.39 & 10.94 \\
\hline Biological regulation & 27.08 & 14.82 & 7.69 & 25.67 & 4.83 & 16.53 & 34.00 & 10.07 \\
\hline Regulation of biological process & 26.49 & 14.82 & 7.69 & 25.67 & 4.83 & - & 33.44 & 10.07 \\
\hline Regulation of cellular process & 25.57 & 14.05 & - & 25.67 & - & - & 33.44 & 10.07 \\
\hline Cellular metabolic process & - & - & 6.26 & - & - & - & - & - \\
\hline Signal transduction & - & - & - & - & 3.73 & - & - & - \\
\hline Response to stimulus & - & - & - & - & - & 18.37 & - & - \\
\hline Cell communication & - & - & - & - & - & 17.59 & - & - \\
\hline \multicolumn{9}{|l|}{ Biochemical function } \\
\hline Binding & 40.31 & 26.66 & 16.61 & 45.84 & 19.76 & 35.06 & 49.87 & 34.45 \\
\hline Nucleotide Binding & 26.25 & 24.31 & 13.61 & 29.04 & 14.26 & 30.82 & 29.74 & 29.11 \\
\hline Purine nucleotide binding & 26.25 & 24.31 & 13.61 & 29.04 & 14.26 & 30.82 & 29.74 & 29.11 \\
\hline Purine ribonucleotide binding & - & - & - & 29.04 & - & 30.82 & 29.74 & - \\
\hline ADP binding & - & - & - & - & 14.26 & - & - & - \\
\hline Adenyl nucleotide binding & 26.25 & 24.31 & 13.61 & - & - & - & - & 29.11 \\
\hline
\end{tabular}

ID: 4kxf.3.A, PDB ID: 3jbl.1.A, PDB ID: 3jbl.1.A, PDB ID: 3jbl.1.A), and LR family CARD Domain-containing Protein 4 (PDB ID: 3jbl.1.A) which indirectly senses specific proteins from pathogenic bacteria and fungi [45, 46]. This paper sheds light on the modeling of eight hypothetical resistance proteins showing homology to the template models which are mainly involved in defense mechanisms. Similar protein modeling carried out and reported on the orthologue of Pi54 designated as Pi54of from Oryza officinalis was studied and modeled $[8,47]$.

\section{Protein structure, function, and validation}

The secondary structure predicted for the eight-resistance protein by using RaptorX showed that residues are involved in the formation of $\alpha$-helix, $\beta$-sheet, and coils structures. Profunc predicts the probable functions based on the 3D structure of the target protein [26]. SuperPose detects the root means square deviation (RMSD) that measures the distance between corresponding residues and accurate models should have $<2.0 \AA$ value [27]. Ramachandran plot of eight resistance proteins confirmed that the modeled structures are following the dihedral angles of the Ramachandran plot and occupied favorable positions (Fig. 5) [2]. Further work is needed to understand the difference between resistance proteins of resistant and susceptible rice cultivars. This can be understood once the structure of effector molecules expressed by the Avr genes of the pathogen is available. Hence, there is a need to elucidate the effector molecules to understand the interaction of resistance proteins and effector proteins.

Disease resistance in plants is more often regulated by a gene-for-gene mechanism in which Avr proteins encoded by pathogens are particularly detected by plant disease $R$ proteins directly or indirectly. Avr proteins trigger defense response elements by changing the membrane ion flux, irreversible plasma membrane damage, production of extracellular reactive oxygen intermediates, and alter in 
Table 7 Superpose predictions of eight resistance proteins

\begin{tabular}{lllllllll}
\hline Gene/RMSD & RP1 & RP2 & RP3 & RP4 & RP5 & RP6 & RP7 & RP8 \\
\hline RP1 & - & 2.01 & 2.22 & 1.65 & 82.15 & 1.45 & 1.56 & 23.22 \\
RP2 & 2.01 & - & 41.79 & 1.96 & 83.68 & 4.23 & 4.33 & 2.68 \\
RP3 & 2.22 & 41.79 & - & 1.83 & 83.80 & 1.39 & 1.43 \\
RP4 & 1.65 & 1.96 & 1.83 & - & 87.09 & 1.69 & 2.05 & 1.80 \\
RP5 & 82.15 & 83.68 & 83.80 & 87.09 & - & 85.11 & 82.23 \\
RP6 & 1.45 & 4.23 & 1.39 & 1.69 & 85.11 & - & 1.06 & 1.78 \\
RP7 & 1.56 & 4.33 & 1.43 & 2.05 & 82.23 & 1.78 & - & 2.35 \\
RP8 & 23.22 & 2.68 & 1.80 & 2.06 & 1.20 & 2.35 & 1.96 \\
\hline
\end{tabular}

gene expression [48]. The protein-protein interaction of Avr and $\mathrm{R}$ proteins becomes evident by the ability of a host to detect pathogen effectors. However, there are relatively few reports on direct interactions between Avr and $R$ proteins [49-52]. Avr proteins presumably enhance the virulence factors by hindering the innate immune systems of host plants in the absence of recognition by $\mathrm{R}$ proteins [53, 54]. Few Avr genes are identified and their protein interactions with resistance protein are yet to be structurally characterized [6].

The present study was aimed to identify the transcripts involved in rice blast resistance in resistant BR2655 and susceptible HR12 cultivars and model the threedimensional structures, function predictions, conserved motifs, and validations of NBS-LRR of eight hypothetical resistance proteins (RP1, RP2, RP3, RP4, R5, RP6, RP7, and RP8) using computational tools. No previous studies are found on this NBS-LRR of eight resistance proteins. Hence, we have modeled the eight resistance proteins, which are found to be stable, with well-defined compact reliable three-dimensional structures, by using highly reputed computational tools. The eight resistance proteins were modeled using SWISS-MODEL, I-TASSER, and RaptorX server tools. The secondary structure predicted by RaptorX and ProFunc displayed the presence of $\alpha$-helix, $\beta$-strands, and random coils. ProFunc, Motif, SuperPose, and Ramachandran plot servers were used to predict the structure and function of eight resistance proteins. These eight resistance proteins will function as a valuable resource for studying the intricate details of the plant defense mechanism.

\section{Conclusions}

In silico studies provide an opportunity to accomplish the modeling and analysis of resistance proteins by employing

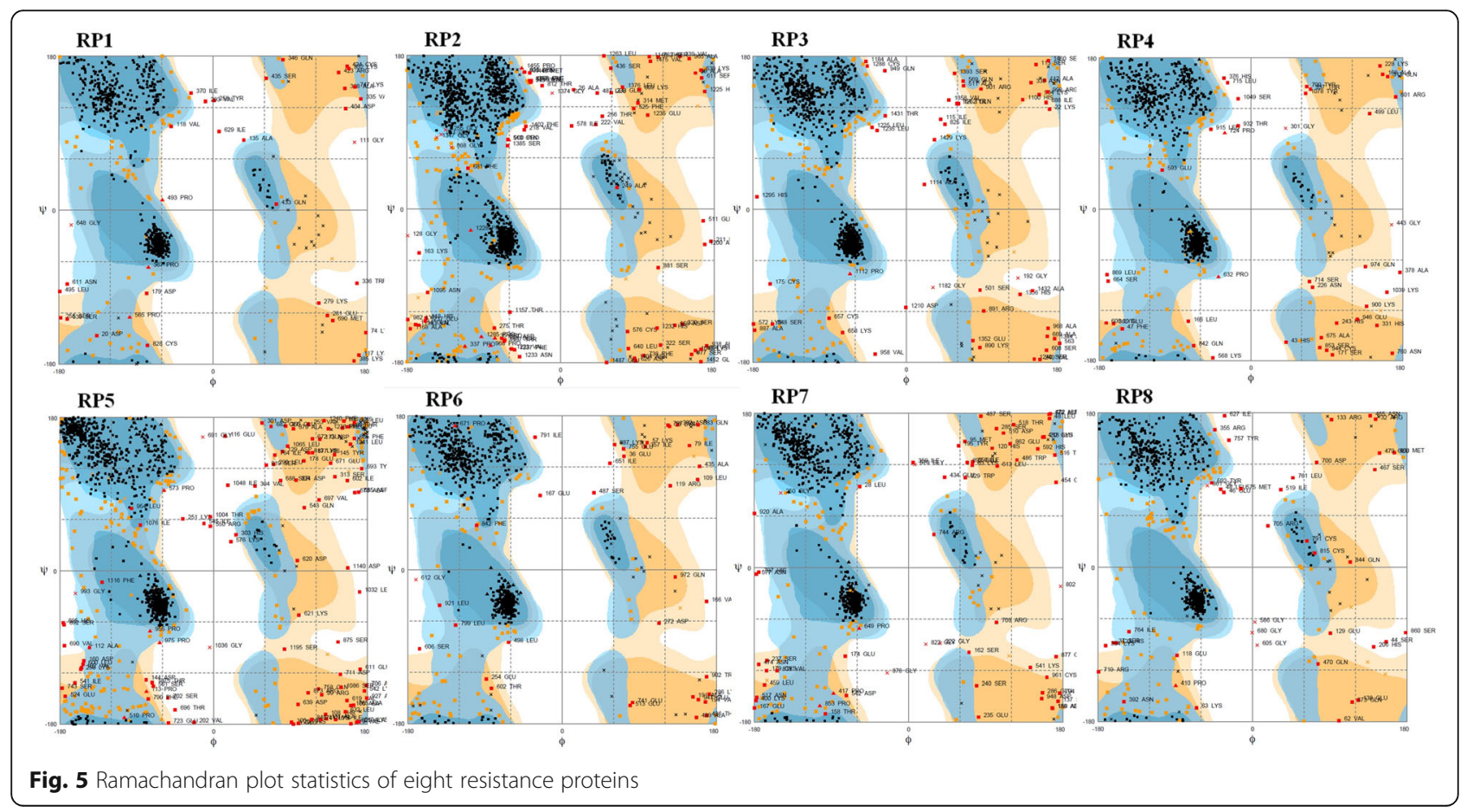


various modeling applications. In the current study, blast resistance transcripts expressed were shortlisted by transcriptomic profiling. Protein sequences of expressed transcripts were selected to determine the physicochemical properties and structures of resistance proteins using in silico techniques. Primary structure analysis revealed that all the resistant and susceptible encoded resistance proteins are rich in leucine residues which seem to correlate with the reported resistance proteins. The secondary structure analysis confirmed that in all the eight sequences, alpha helix dominated, followed by beta turns and then coils. Three-dimensional structure predictions were analyzed by different homology servers, viz., Swiss model and Modeller 9.22. The model structures were validated by a protein structure checking tool called Rampage. The in silico modeled eight resistance proteins are promising candidates for providing insights into domain structures. We hope that further studies with the structure of these resistance proteins and their interactions will provide a better insight into the precise molecular mechanism involved in plant defense.

\section{Abbreviations}

NBS-LRR: Nucleotide-binding site-leucine-rich repeat; RP: Resistance protein; CC: Coiled-coil motif; TIR: Toll-interleukin-1-receptor; DEG: Differentially expressed genes; RMSD: Root means square deviation; PDB: Protein data bank

\section{Acknowledgements}

This work was supported by the Indian Council of Medical Research ICMRSRF (IRIS ID NO. 2014-21680). The authors are grateful to the Department of Plant Pathology, ZARS, V.C. Farm, Mandya, for providing seed materials. We thank Institution of Excellence, University of Mysore, Mysuru, for providing an instrumentation facility. We are also thankful to Yuvaraja's College, University of Mysore, Mysuru, for providing laboratory facilities for carrying out this research work

\section{Authors' contributions}

CR conceptualized and designed the study, acquired and interpreted the data, and was a major contributor in writing and revising the manuscript. SL analyzed, interpreted, and drafted the manuscript. SS involved in acquiring the data and revising the manuscript critically. DNS involved in designing of the study, interpretation of data, revising the manuscript, and final approval of the version to be submitted. The authors have read and approved the manuscript.

\section{Funding}

The research investigation was funded by the Indian Council of Medical Research vide sanction letter ICMR-SRF (IRIS ID NO. 2014-21680). The fund supported the design and collection, analysis, and interpretation of data and in writing the manuscript of the study through the first author who was appointed as a senior research fellow to carry out the current investigation. The role played by the remaining authors in the research investigation and preparation of the manuscript is given under the author's contribution.

\section{Availability of data and materials}

All data generated during this study are included in this manuscript [and its supplementary information].

Ethics approval and consent to participate

Not applicable

\section{Consent for publication}

Not applicable

\section{Competing interests}

The authors declare that they have no competing interests.

\section{Author details}

${ }^{1}$ Department of Molecular Biology, Yuvaraja's College, University of Mysore, Mysuru, Karnataka 570005, India. 'Department of Plant Cell Biotechnology, CSIR-Central Food Technological Research Institute, Mysuru 570020, India.

Received: 24 April 2020 Accepted: 22 September 2020

Published online: 25 November 2020

\section{Supplementary Information}

The online version contains supplementary material available at https://doi. org/10.1186/s43141-020-00076-0.

Additional file 1: Supplementary Data 1, 2, 3 and 4. Supplementary Figures 1 and 2. Tables 1-4.

\section{Author details}

The online version contains supplementary material available at https://doi. org/10.1186/s43141-020-00076-0. 'Department of Molecular Biology, Yuvaraja's College, University of Mysore, Mysuru, Karnataka 570005, India. ${ }^{2}$ Department of Plant Cell Biotechnology, CSIR-Central Food Technological Research Institute, Mysuru 570020, India.

Received: 24 April 2020 Accepted: 22 September 2020

Published online: 25 November 2020

\section{References}

1. Dean RA, Talbot NJ, Ebbole DJ et al (2005) The genome sequence of the rice blast fungus Magnaporthe grisea. Nature 434:980-986

2. Sharma K, Antunes IL, Rajulapati V, Goyal A (2018) Low-resolution SAXS and comparative modelling based structure analysis of endo- $\beta-1,4$-xylanase a family 10 glycoside hydrolase from Pseudopedobacter saltans comb. nov. Int J Biol Macromol 112:1104-1114

3. Liu J, Wang X Mitchell T et al. (2010) Recent progress and understanding of the molecular mechanisms of the rice - Magnaporthe oryzae interaction 11: 419-427. https://doi.org/10.1111/J.1364-3703.2009.00607.X

4. Gururani MA, Venkatesh J, Upadhyaya CP et al (2012) Plant disease resistance genes: current status and future directions. Physiol Mol Plant Pathol 78:51-65

5. DeYoung BJ, Innes RW (2006) Plant NBS-LRR proteins in pathogen sensing and host defence. Nat Immunol 7:1243

6. Li W, Chern M, Yin J et al (2019) Recent advances in broad-spectrum resistance to the rice blast disease. Curr Opin Plant Biol 50:114-120

7. Zhao H, Wang $X$, Jia $Y$ et al (2018) The rice blast resistance gene Ptr encodes an atypical protein required for broad-spectrum disease resistance. Nat Commun 9:2039

8. Devanna NB, Vijayan J, Sharma TR (2014) The blast resistance gene Pi54 of cloned from Oryza officinalis interacts with Avr-Pi54 through its novel nonLRR domains. PLoS One 9:e104840

9. McHale L, Tan X, Koehl P, Michelmore RW (2006) Plant NBS-LRR proteins: adaptable guards. Genome Biol 7:212

10. Doerks T, Von Mering C, Bork P (2004) Functional clues for hypothetical proteins based on genomic context analysis in prokaryotes. Nucleic Acids Res 32:6321-6326

11. Margelevičius M, Venclovas Č (2005) PSI-BLAST-ISS: an intermediate sequence search tool for estimation of the position-specific alignment reliability. BMC Bioinformatics 6:185

12. Schwede T, Kopp J, Guex N, Peitsch MC (2003) SWISS-MODEL: an automated protein homology-modelling server. Nucleic Acids Res 31: 3381-3385

13. Sali A, Blundell TL (1993) Comparative protein modelling by satisfaction of spatial restraints. J Mol Biol 234:779-815

14. Pettersen EF, Goddard TD, Huang CC, Couch GS, Greenblatt DM, Meng EC, Ferrin TE (2004) UCSF chimera - a visualization system for exploratory research and analysis. J Comput Chem 25(13):1605-1612 
15. Adebali O, Ortega DR, Zhulin IB (2014) CDvist: a web server for identification and visualization of conserved domains in protein sequences. Bioinformatics 31:1475-1477

16. Finn RD, Attwood TK, Babbitt PC et al (2016) InterPro in 2017-beyond protein family and domain annotations. Nucleic Acids Res 45:D190-D199

17. Thompson JD, Higgins DG, Gibson TJ (1994) CLUSTAL W: improving the sensitivity of progressive multiple sequence alignment through sequence weighting, position-specific gap penalties, and weight matrix choice. Nucleic Acids Res 22:4673-4680

18. Källberg M, Wang H, Wang S et al (2012) Template-based protein structure modelling using the RaptorX web server. Nat Protoc 7:1511

19. Laskowski RA, Watson JD, Thornton JM (2005) ProFunc: a server for predicting protein function from 3D structure. Nucleic Acids Res 33: W89-W93

20. Mondal D, Ghosh A, Roy D, Kumar A, Shamurailatpam D, Bera S, et al (2017) Yield loss assessment of rice (Oryza sativa L.) due to different biotic stresses under system of rice intensification (SRI).

21. Maiti R, Van Domselaar GH, Zhang H, Wishart DS (2004) SuperPose: a simple server for sophisticated structural superposition. Nucleic Acids Res 32:590-594

22. Ikai A (1980) Thermostability and aliphatic index of globular proteins. J Biochem 88:1895-1898

23. Kanazin V, Marek LF, Shoemaker RC (1996) Resistance gene analogues are conserved and clustered in soybean. Proc Natl Acad Sci 93:11746-11750

24. Dangl JL, Jones JDG (2001) Plant pathogens and integrated defence responses to infection. Nature 411(6839):826

25. Sharma TR, Rai AK, Gupta SK et al (2012) Rice blast management through host-plant resistance: retrospect and prospects. Agric Res 1:37-52

26. Brindha S, Sailo S, Chhakchhuak L, Kalita P, Gurusubramanian G, Kumar JNS (2011) Protein 3D structure determination using homology modelling and structure analysis. Colloquium www science vision in. Citeseer, In, pp 125-133

27. Zhang $Y$ (2008) Progress and challenges in protein structure prediction. Curr Opin Struct Biol 18(3):342-348

28. Wang C, Yang Y, Yuan X et al (2014) Genome-wide association study of blast resistance in indica rice. BMC Plant Biol 14:3-11

29. Bagnaresi $P$, Biselli $C$, Orrù $L$ et al (2012) Comparative transcriptome profiling of the early response to Magnaporthe oryzae in durable resistant vs susceptible rice (Oryza sativa L.) genotypes. PLoS One 7:e51609

30. Mahesh HB, Shirke MD, Singh $S$ et al (2016) Indica rice genome assembly, annotation and mining of blast disease resistance genes. BMC Genomics 17: 1-12. https://doi.org/10.1186/s12864-016-2523-7

31. Matić S, Bagnaresi P, Biselli C et al (2016) Comparative transcriptome profiling of resistant and susceptible rice genotypes in response to the seed-borne pathogen Fusarium fujikuroi. BMC Genomics 17:608

32. Chen J-Y, Huang J-Q, Li N-Y et al (2015) Genome-wide analysis of the gene families of resistance gene analogues in cotton and their response to Verticillium wilt. BMC Plant Biol 15:148

33. Zhao M, Ji H-M, Gao Y, et al (2017) Comparative transcriptome profiling conferring of resistance to Fusarium oxysporum Infection between resistant and susceptible tomato. bioRxiv 116988.

34. Tan S, Wu S (2012) Genome-wide analysis of nucleotide-binding site disease resistance genes in Brachypodium distachyon. Comp Funct Genomics

35. Martin GB, Bogdanove AJ, Sessa G (2003) Understanding the functions of plant disease resistance proteins. Annu Rev Plant Biol 54:23-61

36. Vander Biezen EA, Jones JDG (1998) The NB-ARC domain: a novel signalling motif shared by plant resistance gene products and regulators of cell death in animals. Curr Biol 8(7):R226-R228

37. Jones JDG, Dangl JL (2006) The plant immune system. Nature 444:323-329. https://doi.org/10.1038/nature05286

38. Tameling WIL, Elzinga SDJ, Darmin PS et al (2002) The tomato R gene products $1-2$ and $\mathrm{Ml}-1$ are functional ATP binding proteins with ATPase activity. Plant Cell 14:2929-2939

39. Caicedo AL, Schaal BA, Kunkel BN (1999) Diversity and molecular evolution of the RPS2 resistance gene in Arabidopsis thaliana. Proc Natl Acad Sci 96(1):302-306

40. Dill KA (1990) Dominant forces in protein folding. Biochemistry 29:7133-7155

41. Mattos C (2002) Protein-water interactions in a dynamic world. Trends Biochem Sci. 8. 27(4):203-208.

42. Dodds PN, Rathjen JP (2010) Plant immunity: towards an integrated view of plant-pathogen interactions. Nat Rev Genet 11:539-548
43. Wang, Jizong, Hu M, Wang, Jia, Qi J, Han Z, Wang G, et al (2019) Reconstitution and structure of a plant NLR resistosome conferring immunity. Science (80- ). 364:eaav5870.

44. Keen NT (1990) Gene-for-gene complementarity in plant-pathogen interactions. Annu Rev Genet 24:447-463

45. Inohara N, Nuñez G (2003) Cell death and immunity: NODs: intracellular proteins involved in inflammation and apoptosis. Nat Rev Immunol 3:371

46. Mani A, Sankaranarayanan K (2018) In silico analysis of Natural resistanceassociated Macrophage Protein (NRAMP) family of transporters in rice. Protein J 1-11.

47. Sarkar C, Saklani BK, Singh PK et al (2019) Variation in the LRR region of Pi54 protein alters its interaction with the Avr-Pi54 protein revealed by in silico analysis. PLoS One 14:e0224088

48. Hammond-Kosack KE, Jones JDG (1996) Resistance gene-dependent plant defense responses. Plant Cell 8:1773-1791

49. Deslandes L, Olivier J, Peeters N et al (2003) Physical interaction between RRS1-R, a protein conferring resistance to bacterial wilt, and PopP2, a type III effector targeted to the plant nucleus. Proc Natl Acad Sci U S A 100:8024-8029

50. Dodds PN, Lawrence GJ, Catanzariti AM, Teh T, Wang CIA, Ayliffe M, Kobe B, Ellis JG (2006) Direct protein interaction underlies gene-for-gene specificity and co-evolution of the flax resistance genes and flax rust avirulence genes. Proc Natl Acad Sci U S A 103:8888-8893

51. Jia J, McAdams SA, Bryan GT, Hershey HP, and Valent B (2000) Direct interaction of resistance gene and avirulence gene products confers rice blast resistance. EMBO (Eur. Mol. Biol. Organ.) J. 19:4004-4014.

52. Ueda H, Yamaguchi Y, Sano H (2006) Direct interaction between the tobacco mosaic virus helicase domain and the ATP-bound resistance protein, $\mathrm{N}$ factor during the hypersensitive response in tobacco plants. Plant Mol Biol 61:31-45

53. Dodds PN, Fafiqi M, Gan PHP, Hardham AR, Jones DA, Ellis JG (2009) Effectors of biotrophic fungi and oomycetes: pathogenicity factors and triggers of host resistance. New Phytol 183:993-1000

54. Ellis JG, Dodds PN, Lawrence GJ (2007) The role of secreted proteins in diseases of plants caused by rust, powdery mildew, and smut fungi. Curr Opin Microbiol 10:326-331

\section{Publisher's Note}

Springer Nature remains neutral with regard to jurisdictional claims in published maps and institutional affiliations.

\section{Submit your manuscript to a SpringerOpen ${ }^{\circ}$ journal and benefit from:}

- Convenient online submission

- Rigorous peer review

- Open access: articles freely available online

High visibility within the field

- Retaining the copyright to your article

Submit your next manuscript at $>$ springeropen.com 